\title{
Antimicrobial Activity and Histopathological Safety Evidence of Ochradenus baccatus Delile: A Medicinally Important Plant Growing in Saudi Arabia
}

\author{
Mohsen S. Al-Omar ${ }^{1,2}$, Hussain M. Eldeeb ${ }^{3,4}$, Mugahid A. Mobark ${ }^{5,6}$, Hamdoon A. Mohammed ${ }^{1,7}$ \\ Departments of ' Medicinal Chemistry and Pharmacognosy, ${ }^{4}$ Pharmacology and ${ }^{5}$ Pharmacy Practice, College of Pharmacy, Qassim University, Buraydah 51452, \\ Kingdom of Saudi Arabia, ${ }^{2}$ Department of Medicinal Chemistry and Pharmacognosy, College of Pharmacy, JUST, Jordan, ${ }^{3}$ Department of Medical Biochemistry, Faculty \\ of Medicine, Al-Azhar University, Assiut, ${ }^{7}$ Department of Pharmacognosy, Faculty of Pharmacy, Al-Azhar University, Cairo 11371, Egypt, ${ }^{6}$ Department of Pathology, \\ Faculty of Medicine, University of Kordofan, Al-Ubayyid, Sudan
}

\begin{abstract}
Background: The growing climatic condition affects plant constituents and biological activities. Ochradenus baccatus (Taily Weed) from Resedaceae family is a perennial shrub that is widely used in folk medicine in the Middle East. Aim: From the viewpoint that $O$. baccatus is regularly used in folk medicine, this study was designed to evaluate the antimicrobial activity and investigate the effect of $O$. baccatus on the biochemical and histopathological parameters of liver and kidney in experimental animals. Methods: The $O$. baccatus extracts were obtained by hot continuous extraction method. Agar diffusion and minimal inhibitory concentration assays were used for the antimicrobial activity. 0 . baccatus total extracts at doses of $100 \mathrm{mg} / \mathrm{kg}$ and $50 \mathrm{mg} / \mathrm{kg}$ were given to the first and second groups of rates, respectively, whereas the third and fourth groups received the vehicle olive oil and saline, respectively. The liver and kidney functions, as well as lipid profile and glucose levels, were measured by spectrophotometric technique on obtained blood samples. The liver and kidney tissues were evaluated for histopathological effect. Results: Ethanol and ethyl acetate extracts have similarly and potentially inhibited the bacterial micro-organisms, whereas Candida albicans was inhibited by $n$-hexane extract. $O$. baccatus total extract showed no significant effects on the kidney and liver functions $(P>0.05)$. However, it significantly reduced triglyceride level $(P=0.04)$. The histopathological investigation of liver and kidney tissues revealed no significant differences compared to control animals. Conclusion: The medicinally important plant, $O$. baccatus, growing in Saudi Arabia showed no significant toxic effects on the livers and kidneys. Moreover, it demonstrated a potential antimicrobial activity besides a significant reduction in serum triglycerides in rats. These findings are in consistent with other reported results suggesting no environmental effects on the safety of this plant.

Key words: Antimicrobial activity, histopathology, kidney function, lipid profile, liver function, Ochradenus baccatus

\section{SUMMARY}

- Significant biochemical and histopathological evidence for the safety of Ochradenus baccatus growing in Saudi Arabia were conformed in animal models
\end{abstract}

- Ethanol and ethyl acetate extracts of $O$. baccatus had similarly and potentially inhibited the bacterial micro-organisms, whereas Candida albicans was inhibited by n-hexane extract

- The plant significantly reduced triglyceride level $(P=0.04)$.

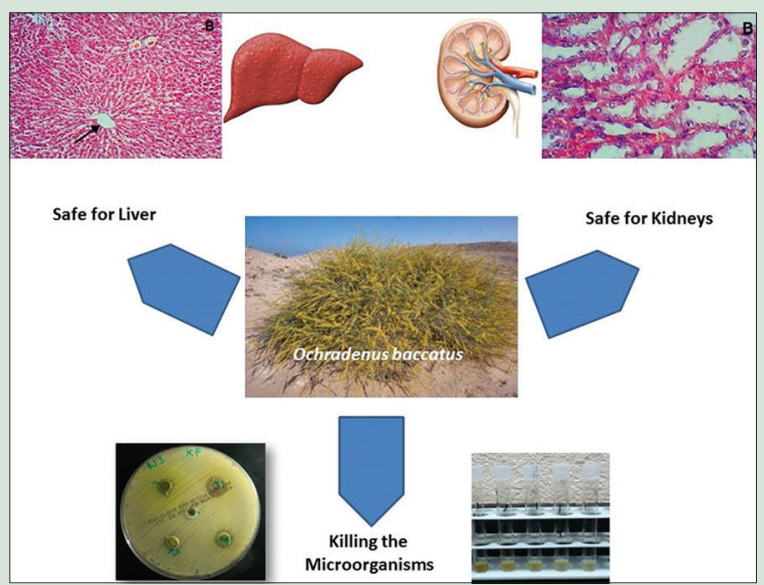

Abbreviations Used: ALT: Alanine aminotransferase, AST: Aspartate transaminase, C. albicans: Candida albicans, E. coli: Escherichia coli, IZD: Inhibition zone diameter, IFCC: International federation of clinical chemistry, $O$. baccatus: Ochradenus baccatus, MIC: Minimal inhibitory concentration, S. aureus: Staphylococcus aureus.

\section{Correspondence:}

Dr. Hamdoon A. Mohammed,

Department of Medicinal Chemistry and Pharmacognosy, College of

Pharmacy, Qassim University, Buraydah 51452, Kingdom of Saudi Arabia.

E-mail: ham.mohammed@qu.edu.sa DOI: 10.4103/pr.pr_103_19

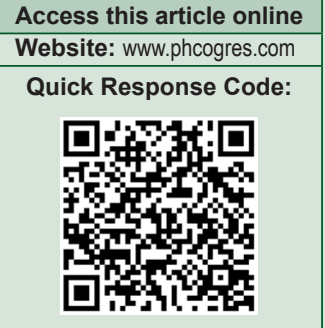

\section{INTRODUCTION}

Ochradenus baccatus (Taily Weed) is a perennial shrub belonging to family Resedaceae and is wildly distributed in the Middle East. The plant is broadly growing in the southwest and focal areas in Saudi Arabia, Ethiopia, Egypt, Libya, and Center East and reaches out into Pakistan. ${ }^{[1]}$ O. baccatus has a great importance in the world, especially in the Arabian Peninsula, as it is used as an important source of food for some species of animals in the deserts. ${ }^{[2]}$ Furthermore, O. baccatus is an important medicinal plant and it contains high contents of antioxidants and anti-inflammatory agents. ${ }^{[3-5]}$ In addition, O. baccatus demonstrates therapeutic importance as it can reduce blood cholesterol levels and induce a potential effect against Plasmodium falciparum. ${ }^{[4]}$
The plant is used in traditional medicine as an anti-inflammatory, ${ }^{[6]}$ in the treatment of male sexual disorders, ${ }^{[7]}$ and as an antibacterial agent. ${ }^{[8]}$

This is an open access journal, and articles are distributed under the terms of the Creative Commons Attribution-NonCommercial-ShareAlike 4.0 License, which allows others to remix, tweak, and build upon the work non-commercially, as long as appropriate credit is given and the new creations are licensed under the identical terms.

For reprints contact: reprints@medknow.com

Cite this article as: Al-Omar MS, Eldeeb HM, Mobark MA, Mohammed HA. Antimicrobial activity and histopathological safety evidence of Ochradenus baccatus Delile: A medicinally important plant growing in Saudi Arabia. Phcog Res 2020;12:131-6. 
The nematicidal activity of the plant against the root-knot nematode Meloidogyne javanica was evaluated, and it has been found to contain exceptionally high levels of glucosinolates. ${ }^{[9]}$ The plant extract showed an antimalarial effect, and it induces apoptosis in HepG2 cells, which indicates that it has anticancer activity. ${ }^{[10,11]}$

$O$. baccatus is equipped with antioxidant machinery which includes major antioxidant enzymes such as superoxide dismutase, catalase, ascorbate peroxidase, and glutathione reductase. In addition, the plant is also equipped by antioxidant secondary metabolite, particularly flavonoids. The mentioned antioxidant machinery is the protective pathway of the plant to overcome oxidative stress produced by salinity condition of the plant's environment. ${ }^{[12]}$

Flavonoid glycosides, particularly flavonol-type glycosides, were isolated from the aerial part of $O$. baccatus. In addition, most of these flavonol glycosides have been elucidated as quercetin derivatives. New flavonoids quercetin 3-O- $\beta$-glucosyl $(1 \rightarrow 2)$ - $\alpha$-rhaminoside-7-O- $\alpha$ -rhaminoside and quercetin3-O-pcoumaryl $(1 \rightarrow 6)$ - $\beta$-glucosyl $(1 \rightarrow$ $6)-\beta$-glucoside-7-O- $\alpha$ rhaminoside, together with known compounds quercetin 3-gentiobioside, isoquercetin, quercetin, and kaempferol, were isolated from the aerial part of O. baccatus. ${ }^{[12]}$ Furthermore, O. baccatus also contains alkaloids, coumarins, saponins, and steroidal compounds. ${ }^{[13]}$ Such medicinally important plant with huge number of bioactive secondary metabolites might affect the liver and kidney as they are important organs for metabolism and excretion of the metabolites. ${ }^{[14-16]}$ Accordingly, such plant needs to be investigated for its deleterious effects in the functions of liver and kidney. In that regard, a study was conducted for the O. baccatus ethanol extract that was collected from the Eastern Desert of Egypt. The study concluded that the plant is safe in animal trials. ${ }^{[5]}$ The current study evaluated the antimicrobial activity, liver and kidney effects, and histopathological changes induced by O. baccatus extracts collected from Saudi Arabia and widely used as a medicinal plant.

\section{MATERIALS AND METHODS}

\section{Plant materials and extraction procedure}

The plant was collected in September 2017 from Hnakya in Medina Region in Saudi Arabia and identified as O. baccatus by Prof. Ahmed Al-Oglah taxonomist from the Department of Biology, Yarmouk University, Jordan. The whole plant was dried in open air shade and ground in $3 \mathrm{~mm}$ mesh mill.

Accurately, $400 \mathrm{~g}$ of the dried plant was extracted by Soxhlet extractor ${ }^{[17]}$ using n-hexane, chloroform, ethyl acetate, and ethanol in sequence (10 refluxes for each). The extracts were vacuum-dried at $40^{\circ} \mathrm{C}$ until complete dryness. In the same manner, ethanol was used to extract $400 \mathrm{~g}$ of $O$. baccatus to collect the total ethanol extract that was used in the animal experiments. The dried extracts were stored at $-20^{\circ} \mathrm{C}$ for further steps. Each dry extract has been weighted and the extractive values were calculated using the equation:

$$
\text { Extraction value }(\%)=\frac{\begin{array}{c}
\text { The weight of dried extract obtained } \\
\text { from each solvent in gram }
\end{array}}{\text { Weight of dried plant materials }} \times 100
$$

\section{Antimicrobial assay of plant extract Microbial strains}

The micro-organisms were provided by the Medical Microbiology Department, College of Applied Medical Sciences, Qassim University, Buraydah, Saudi Arabia. Only three micro-organisms were used in the assay, which were Gram positive, Staphylococcus aureus; Gram negative, Escherichia coli; and the fungus, Candida albicans.

\section{Agar well-diffusion assay}

The procedure followed the method of Cooper and Woodman. ${ }^{[18]}$ The prepared microbial suspensions were incubated till turbidity/growth comparable to $0.5 \mathrm{McF}$ arland tube was obtained. Sterile swaps were smeared on the agar surface and incubated for few minutes; then, $75 \mu \mathrm{l}$ of the extracts (prepared in DMSO $10 \mathrm{mg} / \mathrm{ml}$ ) was pipetted to the designed cups. Positive control drug disc $(10 \mu \mathrm{g} / \mathrm{ml}$ amoxicillin, gentamicin, and clotrimazole) was placed onto the top of the inoculated agar plate. Plates were then incubated (Sheldon Manufacturing Inc., USA) for 24-72 h depending on the growth rate of each microbial organism and were checked every day, and inhibition zone diameters (IZDs) were measured to the nearest millimeter. ${ }^{[19,20]}$

\section{Minimal inhibitory concentration assay}

The broth microdilution assay was used according to the method described by Candan et al. ${ }^{[21]}$ The bacterial organisms were cultured overnight at $37^{\circ} \mathrm{C}$ in Mueller Hinton broth supplemented with Tween 80 detergent (final concentration of $0.5 \%[\mathrm{v} / \mathrm{v}]$ ), whereas C. albicans was cultured overnight at $30^{\circ} \mathrm{C}$ in Sabouraud dextrose broth + Tween 80. Serial dilutions of the extracts were prepared in a 96-well microplate and incubated at $37^{\circ} \mathrm{C}$ for $24 \mathrm{~h}$ for bacteria and at $30^{\circ} \mathrm{C}$ for $48 \mathrm{~h}$ for C. albicans. The white turbidity in well bottom indicates the bacterial growth. ${ }^{[22]}$

Total extract effect on the liver, kidney, blood glucose, cholesterol, and triglyceride levels in the rats

\section{Experimental animals}

The experiment was performed using 24 male albino rats weighing 190-230 g that were obtained from animal house of College of Pharmacy, Qassim University, KSA. Animals were maintained at the animal house with standard conditions. The animals were divided randomly into four groups in which each group contains six animals. The study was approved by the Ethical Committee of College of Pharmacy, Qassim University, KSA. The handling and care of experimental rats were according to internationally accepted regulations.

\section{Toxicity and determination of $\mathrm{LD}_{50}$ of Ochradenus baccatus extract}

The $\mathrm{LD}_{50}$ of the $O$. baccatus ethanol extract was determined using the fifth group of the male albino rats and according to the method described by Lorke. ${ }^{[23]}$ The animals received 1000, 2000, or $4000 \mathrm{mg} / \mathrm{kg}$ of the extract and were investigated for $24 \mathrm{~h}$.

\section{Doses preparation and experimental study plan}

$50 \mathrm{mg} / \mathrm{kg}$ and $100 \mathrm{mg} / \mathrm{kg}$ of ethanol extract were used as therapeutic doses which are equal to $1 / 80$ and $1 / 40$, respectively, of the maximum dose $(4000 \mathrm{mg} / \mathrm{kg})$ that produces no mortality or acute toxicity. The first and second groups of the rats received $100 \mathrm{mg} / \mathrm{kg}$ and $50 \mathrm{mg} / \mathrm{kg}$ of the $O$. baccatus extract dissolved in olive oil, respectively. The third and fourth groups were used as placebo which received only olive oil vehicle and saline, respectively. All the doses were administrated to the rats orally using orogastric cannula for consecutive 30 days. By the end of therapeutic regimen, blood samples were obtained by retro-orbital puncture after anesthesia by diethyl ether. Serum was separated for biochemical assays using spectrophotometric procedure. For histopathological examination, livers and kidneys were dissected after rats' scarification, then fixed in $10 \%$ formalin, and left for $24 \mathrm{~h}$ for proper fixation.

\section{Measurements of liver, kidney, lipid profile, and blood glucose} levels

The serum level of total protein was measured photometrically using colorimetric test from human company, according to the method 
of Weichselbaum in $1946 .{ }^{[24]}$ The determination of serum glucose, cholesterol, and triglycerides was determined by colorimetric methods. ${ }^{[25]}$ The serum level of ALT and AST was determined using optimized UV test according to the International Federation of Clinical Chemistry (IFCC). ${ }^{[2]}$ Serum creatinine was determined by kinetic method without deproteinization - Jaffe reaction. The urea was determined by enzymatic colorimetric, endpoint Berthelot method. All the kits were supplied from Crescent Diagnostics Company in Saudi Arabia.

\section{Histological evaluation of liver and kidney tissues}

The formalin-fixed tissue was processed using an automated tissue processor instrument (Leica TP1020), and paraffin-imbedded sections were prepared. Serial $3-5-\mu \mathrm{m}$ sections were prepared using microtome (Leica RM2245) and stained by hematoxylin and eosin stain. All tissue sections were examined by light microscope (Olympus BX41) using $\times 4, \times 10$, and $\times 40$ magnifications, and images were taken through digital image camera (5MP Binocular Microscope Electronic Eyepiece USB Video CMOS Camera for Image Capture) and analyzed by ToupView image analyzer. Arteriolosclerosis was graded as described by Sommers et al. ${ }^{[27]}$ Grade 0 indicated unaltered arterioles, Grade 1 described minor localized thickening, and Grade 2 represented thickened wall that equaled to the lumen. Grade 3 described arterioles with wall thickness exceeding the diameter of the lumen.

\section{Statistical analysis}

One-way ANOVA followed by Tukey-Kramer multiple comparison test using SPSS (IBM Cooperation) statistical program was used in the analysis of data, and $P<0.05$ was considered statistically significant.

\section{RESULTS}

\section{The extractive values and antimicrobial activity of Ochradenus baccatus extracts}

Different polar solvents were used to extract $O$. baccatus in hot continuous extractor (Soxhlet apparatus) extract. The extractive values were determined for each solvent by calculating the percentage of the dried extract materials obtained from dried plant powders as extracted by $n$-hexane, chloroform, ethyl acetate, and ethanol in sequence. The results obtained from extractive value calculations indicate that more polar solvents such as ethanol and ethyl acetate have the ability to extract the plant materials more than less polar solvents [Table 1]. The antimicrobial testing of $O$. baccatus was conducted for plant extracts against three microbial organisms including Gram positive (S. aureus), Gram negative (E. coli), and C. albicans. The results showed that the growths of the two tested bacterial micro-organisms were strongly inhibited by ethanol and ethyl acetate extracts which were similarly inhibited the growth of $S$. aureus and E. coli by $17 \mathrm{~mm}$ and $12 \mathrm{~mm}$ IZD, respectively. However, ethanol extract showed smaller minimal inhibitory concentration (MIC) values compared to ethyl acetate extract against both micro-organisms [Table 1]. Both ethanol and ethyl acetate extracts were inactive against C. albicans. Inversely, C. albicans was strongly inhibited by $\mathrm{n}$-hexane and chloroform extract with $19 \mathrm{~mm}$ IZD (3.5 mg/ml MIC) and $15 \mathrm{~mm} \mathrm{IZD} \mathrm{(11} \mathrm{mg/ml} \mathrm{MIC),}$ respectively [Table 1].

\section{Biochemical results}

This study showed no significant differences in the serum levels of blood urea, serum creatinine, and blood glucose between the treated rats' groups ( 1 and 2 ) and the controls' groups ( 3 and 4 ) as $P=0.9,0.26$, and 0.57 , respectively. With regard to the effect of $O$. baccatus on liver function, the study also showed no significant difference in the serum level of ALT, AST, and total protein between the treated rats' groups (1 and 2) and the controls' groups (3 and 4) with resultant $P=0.16,0.30$, and 0.18 , respectively [Table 2]. These results indicated that $O$. baccatus is safe to the kidneys and livers with no effect on the level of blood glucose [Table 3].

Furthermore, O. baccatus total extract showed no significant difference in the serum level of cholesterol in the treated rats' groups compared with the controls' groups as $P=0.22$. However, the serum levels of triglycerides were significantly decreased in Group 1 that received $100 \mathrm{mg} / \mathrm{kg}$ of the $O$. baccatus extract compared to the control groups $(P=0.04)$, and these findings suggested a hypolipidemic effect of $O$. baccatus extract [Table 2 and Figure 1].

\section{Histopathological evaluation of rats' livers and kidneys}

This study showed no significant difference in both the mean glomerular diameter and the mean Bowman's space diameter between the tested rats' groups and the controls' groups with $P=0.133$ and 0.1473 , respectively.

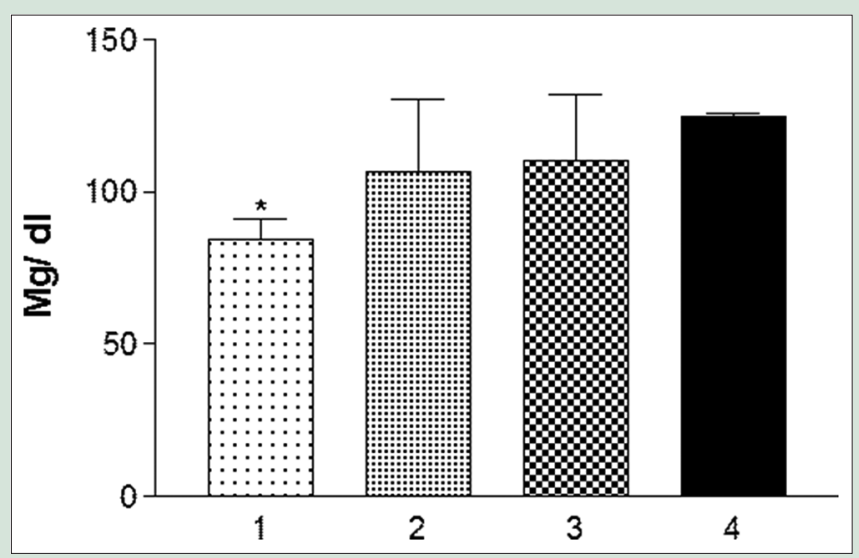

Figure 1: The serum level of triglycerides in treated rats with Ochradenus baccatus as compared to controls

Table 1: Extractive values and antimicrobial activity of Ochradenus baccatus extracts

\begin{tabular}{|c|c|c|c|c|c|c|c|}
\hline \multirow[t]{3}{*}{ Extracts } & \multirow{3}{*}{$\begin{array}{l}\text { Extractive } \\
\text { values (\%) }\end{array}$} & \multicolumn{6}{|c|}{ Antimicrobial activity } \\
\hline & & \multicolumn{2}{|c|}{ Staphylococcus aureus } & \multicolumn{2}{|c|}{ Escherichia coli } & \multicolumn{2}{|c|}{ Candida albicans } \\
\hline & & IZD* & $\mathrm{MIC}^{* *}$ & IZD & MIC & IZD & MIC \\
\hline Ethanol & 3 & 17 & $7.5 \pm 0.25$ & 12 & $17.0 \pm 1.22$ & 0 & ND \\
\hline Ethyl acetate & 2.77 & 17 & $8.25 \pm 0.22$ & 12 & $20.1 \pm 0.97$ & 0 & ND \\
\hline Chloroform & 2.15 & 12 & $22.5 \pm 1.19$ & 0 & ND & 15 & $11.0 \pm 0.75$ \\
\hline$n$-hexane & 1.25 & 0 & ND & 10 & ND & 19 & $3.5 \pm 0.14$ \\
\hline
\end{tabular}

${ }^{*}$ IZD was calculated to the nearest millimeter, ${ }^{* *} \mathrm{MIC}$ was calculated in $\mathrm{mg} / \mathrm{ml}$ from three independent measurements \pm SD. ND: Indicating that MIC not detected until $100(\mathrm{mg} / \mathrm{ml})$ of the extracts. MIC: Minimal Inhibitory Concentration; IZD: Inhibition zone diameters, SD: Standard deviation 
Moreover, there was no significant arteriolosclerosis nor significant inflammatory cells infiltrate between all the studied groups [Table 4].

The histopathological evaluation of the renal tissues obtained from Groups 1, 2, and 3 revealed that the glomerular structures, interstitium, blood vessels, and renal tubules were preserved and well organized without evidence of inflammatory cellular infiltration or necrosis which indicated insignificant histopathological changes. Group 4 showed significant hyaline droplets in the renal tubules and on other significant changes in the other renal structures [Figures 2 and 3]. The liver tissue from all the four groups showed that the liver architecture, sinusoids, central vein, and portal tract were intact and well preserved without any evidence of porto-portal or porto-central inflammation, or necrosis which signifies no histopathological changes [Figure 4].

\section{DISCUSSION}

O. baccatus is a medicinally important plant used in different areas of traditional medicine in many countries. The plant is the reach of complex natural secondary metabolites, particularly flavonoids, alkaloids, saponins, and sterols. One previous study had investigated the

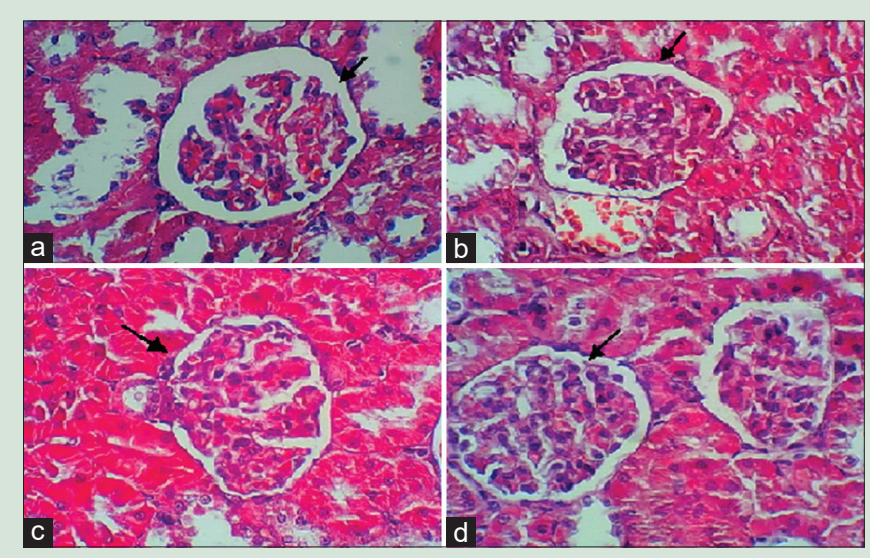

Figure 2: Renal glomeruli showed insignificant changes, (a) Group 1, (b) Group 2, (c) Group 3, (d) Group 4

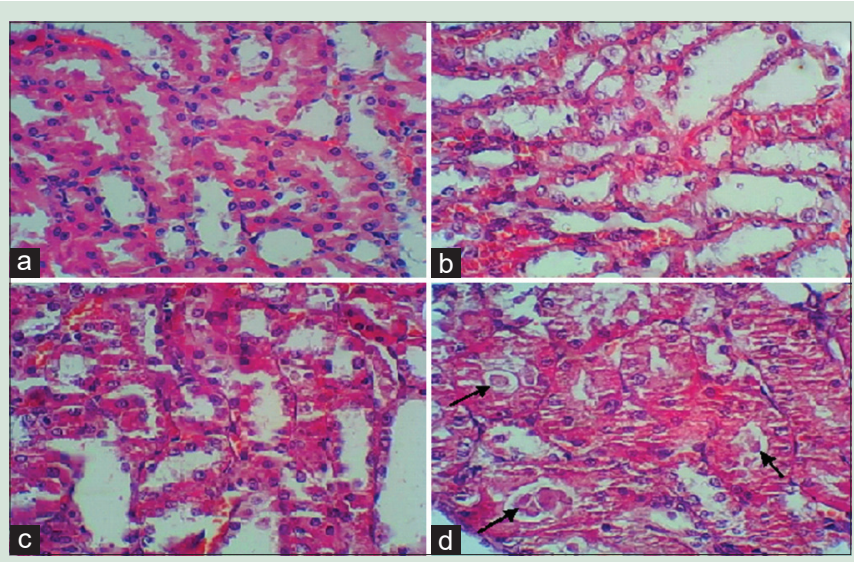

Figure 3: Renal tubules, (a) Group 1, (b) Group 2, (c) Group 3, (d) Group 4 showed significant hyaline droplets (arrow)

Table 2: The serum level of alanine aminotransferase, aspartate transaminase, total protein, cholesterol, and triglycerides in treated rats with hexane extract of Ochradenus baccatus compared to controls

\begin{tabular}{lccccc}
\hline Groups & \multicolumn{3}{c}{ Mean \pm SD } & Total cholesterol \\
\cline { 2 - 5 } & ALT & AST & Total protein & $64.99 \pm 7.91$ & $76.21 \pm 1.18$ \\
Group 1 & $38.71 \pm 13.81$ & $56.48 \pm 15.24$ & $5.66 \pm 0.27$ & $81.53 \pm 7.57$ & $106.7 \pm 23.73$ \\
Group 2 & $23.85 \pm 5.28$ & $35.22 \pm 11.70$ & $5.92 \pm 0.72$ & $110.3 \pm 21.59$ \\
Group 3 & $31.09 \pm 5.73$ & $30.78 \pm 25.76$ & $6.54 \pm 0.23$ & $76.02 \pm 14.08$ & $125.1 \pm 0.85$ \\
Group 4 & $42.26 \pm 10.58$ & $39.98 \pm 5.03$ & $6.78 \pm 0.94$ & 0.22 (NS) \\
$P$ & 0.16 (NS) & 0.30 (NS) & 0.18 (NS) & $0.04^{*}$ \\
\hline
\end{tabular}

Results are expressed as mean \pm SD. Group 1: Treated rats with 100 (mg/kg) of extract, Group 2: Treated rats with 100 (mg/kg) of extract; Group 3: Treated rats with olive oil as a vehicle; Group 4: Rats received saline. ALT: Alanine aminotransferase; AST: Aspartate transaminase; SD: Standard deviation; NS: Not significance

Table 3: The serum level of urea creatinine and glucose in treated rats with hexane extract of Ochradenus baccatus compared to controls

\begin{tabular}{lccc}
\hline Groups & & Mean \pm SD & Blood glucose \\
\cline { 2 - 4 } & Blood urea & Serum creatinine & $118.4 \pm 13.78$ \\
Group 1 & $68.31 \pm 1.28$ & $0.718 \pm 0.10$ & $98.25 \pm 13.29$ \\
Group 2 & $68.51 \pm 2.02$ & $0.837 \pm 0.07$ & $116.2 \pm 32.38$ \\
Group 3 & $67.92 \pm 1.46$ & $0.8087 \pm 0.06$ & $118.8 \pm 15.2$ \\
Group 4 & $68.61 \pm 0.59$ & $0.8967 \pm 0.15$ & 0.57 (NS) \\
$P$ & 0.9 (NS) & 0.26 (NS) & \\
\hline
\end{tabular}

Results are expressed as mean \pm SD. Group 1: Treated rats with 100 (mg/kg) of extract, Group 2: Treated rats with 100 (mg/kg) of extract, Group 3: Treated rats with olive oil as a vehicle, Group 4: Rats received saline. SD: Standard deviation; NS: Not significance

Table 4: Mean glomerular and Bowman's space diameter \pm standard deviation, grade of arteriolosclerosis, and degree of inflammation

\begin{tabular}{lcccc}
\hline & Group 1 & Group 2 & Group 3 & Group 4 \\
\hline Mean glomerular diameter $\pm \mathrm{SD}(\mu \mathrm{m})$ & $170.08 \pm 2.32$ & $168.77 \pm 1.38$ & $170.97 \pm 0.64$ & $169.93 \pm 1.30$ \\
Mean Bowman's space diameter $\pm \mathrm{SD}(\mu \mathrm{m})$ & $22.73 \pm 0.70$ & $22.55 \pm 0.44$ & $21.78 \pm 0.24$ & $22.40 \pm 0.54$ \\
Arteriolosclerosis & Grade 0 & Grade 0 & Grade 0 & Grade 0 \\
Inflammatory cell infiltrate & Insignificant & Insignificant & Insignificant & Insignificant \\
\hline
\end{tabular}

Results are expressed as mean \pm SD. Group 1: Treated rats with 100 (mg/kg) of extract, Group 2: Treated rats with 100 (mg/kg) of extract, Group 3: Treated rats with olive oil as a vehicle, Group 4: Rats received saline. SD: Standard deviation 


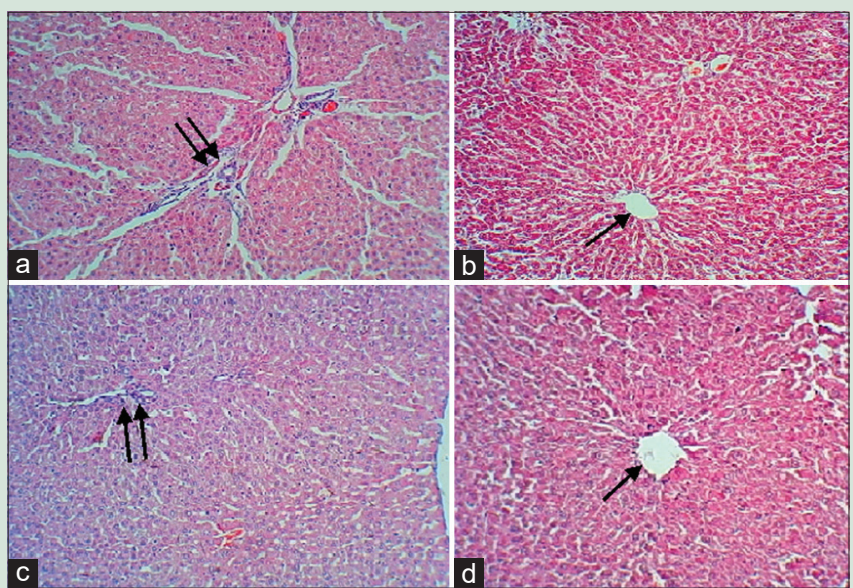

Figure 4: The liver tissue, (a) Group 1, (b) Group 2, (c) Group 3, (d) Group 4 showed insignificant changes, central vein (single arrow) portal tract (double arrow)

acute and chronic toxicity of $O$. baccatus growing in Egypt. The study concluded that the plant growing in that climatic region was safe until $4000 \mathrm{mg} / \mathrm{kg}$ as a daily dose in rats. ${ }^{[5]}$ The differences in climatic condition such as temperature and humidity regularly affect the plant constituents, therapeutic effects, and toxicity. ${ }^{[28-31]}$ The biochemical markers were investigated in the present study for O. baccatus growing in Saudi Arabia. Moreover, the histopathological effects on the liver and kidney tissues of treated and controlled rats were investigated.

Antimicrobial activity of $O$. baccatus was conducted on different plant extracts. Polar extracts (ethanol and ethyl acetate extracts) of $O$. baccatus were active against bacterial micro-organism $S$. aureus and E. coli, whereas non-polar extracts (chloroform and n-hexane extracts) had exerted activity against fungal strain C. albicans.

The serum level of ALT, AST, and total protein showed no significant differences in treated rats with extract of O. baccatus as compared to controls [Table 2]. The same results were provided by histopathological examination of liver tissues of treated rats with extract in comparison with the control group where all the groups showed no detectable changes in liver histology of sinusoids, portal tracts, or central vein [Figure 4]. These results are in accordance with the results obtained from $O$. baccatus growing in Egypt ${ }^{[5]}$ and insure that the extract of O. baccatus is considered safe to the liver cells without signs of hepatic toxicity.

The extract of $O$. baccatus has significantly reduced the serum level of triglycerides, especially in the first group of animals which received the dose of the extract $(100 \mathrm{mg} / \mathrm{kg})$ with $P=0.04$. Although there was no significant effect on the serum level of cholesterol and glucose in the treated group compared to the control group in this study [Table 2], another study done by Barakat et al. showed a significant hypocholesterolemic effect of $O$. baccatus in rats, and they attributed their findings to the flavonoid contents. ${ }^{[12]}$ Furthermore, Saleh et al. indicated that the antioxidant and anti-inflammatory effect of the O. baccatus extract may result in a hypolipidemic of this extract. ${ }^{[5]}$

Concerning the effects on the kidneys, this study indicated that $O$. baccatus extract showed no significant differences on blood creatinine and urea; the main kidney function tests of the treated rats were compared with controls, which indicated that there is no toxic effect on the kidney [Table 3]. In correlating the chemical findings to the histopathological examination, the mean glomerular diameter and the mean diameter of the Bowman's space in all the studied four groups showed no statistically significant differences between groups using one-way ANOVA test with $P=0.133$ and 0.1473 , respectively [Table 4]. In all studied groups the renal arterioles showed no wall thickening, hyaline changes or fibrinoid necrosis. Moreover, no significant inflammatory cellular infiltrate was seen. However, the renal tubules demonstrated prominent hyaline droplets in Group 4 that treated with saline, these findings open future challenges for further studies on the effect of saline in renal tubules [Figure 3].

\section{CONCLUSION}

O. baccatus extracts showed potential antimicrobial activity against $S$. aureus, E. coli, and C. albicans. In addition, the total plant extract was considered to be safe and has no toxic effects in kidney and liver in treated rats for 30 days with $50 \mathrm{mg} / \mathrm{kg}$ and $100 \mathrm{mg} / \mathrm{kg}$ compared to controls as evidenced by biochemical and histopathological evaluation. Moreover, the extracts significantly reduced the serum level of triglycerides, especially at the higher dose. Similar results were reported for O. baccatus growing in a different climatic region, i.e., Egypt, which suggests no environmental effects on the safety of this plant.

\section{Acknowledgements}

The authors are acknowledging Dr. Sultan Sajed, Mr. Khalid Almotairy, and Yazeed Alneef and Khaled Alhabeeb for their help.

\section{Financial support and sponsorship}

Nil.

\section{Conflicts of interest}

There are no conflicts of interest.

\section{REFERENCES}

1. El-Wahab RH, Zaghloul MS, Kamel WM, Moustafa AR. Diversity and distribution of medicinal plants in North Sinai, Egypt. Afr J Environ Sci Technol 2008;2:157-71.

2. Bhatt A, Pérez-García F. Seed dormancy of Ochradenus baccatus (Resedaceae), a shrubby species from Arabian Desert regions. Rev Biol Trop 2016;64:965-74.

3. Gourley GK, Holt JM, Thornton CW. Casebook for Textbook of Therapeutics: Drug and Disease Management. London: Lippincott Williams \& Wilkins; 2000.

4. Qurainy AF, Nadeem M, Khan S, Alansi S, Tarroum M. Efficient regeneration of a potential medicinal plant Ochradenus baccatus Delile from cotyledon and shoot axis. Pak J Bot 2013;45:501-5

5. Alqasoumi SI, Soliman G, Awaad AS, Donia A. Anti-inflammatory activity, safety and protective effects of Leptadenia pyrotechnica, Haloxylon salicornicum and Ochradenus baccatus in ulcerative colitis. Phytopharmacology 2012;2:58-71.

6. Al-Qurainy F, Nadeem M, Khan S, Alansi S, Tarroum M, Al-Ameri A. Synseed production for storage and conservation of Ochradenus baccatus Delile. Pak J Bot 2014;46:897-902

7. Soliman GA, Donia Ael R, Awaad AS, Alqasoumi SI, Yusufoglu H. Effect of Emex spinosa, Leptadenia pyrotechnica, Haloxylon salicornicum and Ochradenus baccatus extracts on the reproductive organs of adult male rats. Pharm Biol 2012;50:105-12

8. Abdel-Sattar EA, Harraz FM, Gayed SH. Antimicrobial activity of extracts of some plants collected from the Kingdom of Saudi Arabia. J Med Sci 2008;15:1-2

9. Oka Y, Shuker S, Tkachi N, Trabelcy B, Gerchman Y. Nematicidal activity of Ochradenus baccatus against the root-knot nematode Meloidogyne javanica. Plant Pathol 2014;63:221-31.

10. Bhatia D, Mandal A, Nevo E, Bishayee A. Apoptosis-inducing effects of extracts from desert plants in HepG2 human hepatocarcinoma cells. Asian Pac J Trop Biomed 2015;5:87-92.

11. Abdel-Sattar E, Maes L, Salama MM. In vitro activities of plant extracts from Saudi Arabia against malaria, leishmaniasis, sleeping sickness and Chagas disease. Phytother Res 2010;24:1322-8.

12. Barakat HH, El-Mousallamy AM, Souleman AM, Awadalla S. Flavonoids of Ochradenus baccatus. Phytochemistry 1991;30:3777-9.

13. Hussain $\mathrm{HH}$, El-Oqlah AA. Chemical constituents of plants growing in Bahrain Int J Pharmacogn 1997;35:147-9.

14. Seeff LB, Lindsay KL, Bacon BR, Kresina TF, Hoofnagle JH. Complementary and alternative medicine in chronic liver disease. Hepatology 2001;34:595-603. 
15. Schoental R. Liver disease and "natural" hepatotoxins. Bull World Health Organ 1963;29:823-33

16. Asif M. A brief study of toxic effects of some medicinal herbs on kidney. Adv Biomed Res 2012;1:44.

17. Luque de Castro MD, Priego-Capote F. Soxhlet extraction: Past and present panacea. J Chromatogr A 2010;1217:2383-9.

18. Cooper KE, Woodman D. The diffusion of antiseptics through agar gels, with special reference to the agar cup assay method of estimating the activity of penicillin. J Pathol Bacteriol 1946;58:75-84.

19. Mohammed HA, Al-Omer MS, Ahmed AM, Hashish NE, Alsaedi HM, Alghazy SA, et al. Comparative study for the volatile oil constituents and antimicrobial activity of Rhanterium epapposum Oliv. Pharmacogn $J$ 2019;11:195-9.

20. Kavanagh F. Dilution methods of antibiotic assays. In: Analytical Microbiology London: Elsevier; 1963. p. 125.

21. Candan F, Unlu M, Tepe B, Daferera D, Polissiou M, Sökmen A, et al. Antioxidant and antimicrobial activity of the essential oil and methanol extracts of Achillea millefolium subsp. millefolium Afan. (Asteraceae). J Ethnopharmacol 2003;87:215-20

22. Mohammed HA, Al-Omar MS, Aly MS, Hegazy MM. Essential oil constituents and biological activities of the halophytic plants, Suaeda vermiculata Forssk and Salsola cyclophylla Bakera growing in Saudi Arabia. Journal of Essential Oil Bearing Plants 2019;22:82-93.

23. Lorke D. A new approach to practical acute toxicity testing. Arch Toxicol
1983;54:275-87.

24. Weichselbaum TE $A n$ accurate and rapid method for the determination of proteins in small amounts of blood serum and plasma. Am J Clin Pathol 1946;10:40-9

25. Zhang XF, Tan BK. Effects of an ethanolic extract of Gynura procumbens on serum glucose, cholesterol and triglyceride levels in normal and streptozotocin-induced diabetic rats. Singapore Med J 2000;41:9-13.

26. Thefeld W, Hoffmeister H, Busch EW, Koller PU, Vollmar J. Reference values for the determination of GOT, GPT, and alkaline phosphatase in serum with optima standard methods. Dtsch Med Wochenschr 1974;99:343-51.

27. Sommers SC, Relman AS, Smithwick RH. Histologic studies of kidney biopsy specimens from patients with hypertension. Am J Pathol 1958;34:685-715.

28. Figueiredo AC, Barroso JG, Pedro LG, Scheffer JJC. Factors affecting secondary metabolite production in plants: Volatile components and essential oils. Flavour Fragr J 2008;23:213-26

29. Downey MO, Dokoozlian NK, Krstic MP. Cultural practice and environmental impacts on the flavonoid composition of grapes and wine: A review of recent research. Am J Enol Vitic 2006:57:257-68.

30. DaMatta FM, Grandis A, Arenque BC, Buckeridge MS. Impacts of climate changes on crop physiology and food quality. Food Res Int 2010;43:1814-23.

31. Mohammed HA, Abdel-Aziz MM, Hegazy MM. Anti-Oral Pathogens of Tecoma stans (L.) and Cassia javanica (L.) Flower Volatile Oils in Comparison with Chlorhexidine in Accordance with Their Folk Medicinal Uses. Medicina 2019;55:301-10 